\title{
Financial Literacy Education in Museum: Investigating the Relationship between Students' Motivation, Satisfying Experiences and Generic Learning Outcomes
}

\author{
Mohd Halim Mahphoth ${ }^{1}$, Shafinar Ismail ${ }^{2}$, Mohd Isham Abidin ${ }^{3}$, Rohaiza Kamis ${ }^{4}$, Wei-Loon \\ $\mathrm{Koe}^{5}$, Puspo Dewi Dirgantari ${ }^{6}$ \\ \{mohdhalim282@gmail.com ${ }^{1}$ \} \\ Universiti Teknologi MARA, Malaysia ${ }^{1,2,3,4,5}$ \\ Universitas Pendidikan Indonesia, Indonesia ${ }^{6}$
}

\begin{abstract}
Over the last several years, the issue of financial literacy seems to have risen on the agendas of the young generation. For youth in the Malaysian context, the needs for financial literacy are increasingly significant. The Bank Negara Malaysia Museum Art and Gallery (BNM MAG) fortunately educates the public through exhibitions that encourage financial literacy understanding by visitors. The research explored the links between motivation, satisfying experiences and generic learning outcomes of BNM MAG's visitors. The study showed four important satisfying experiences which had major and positive effects on young visitors' generic learning results, including affective, cognitive, sensory and social experiences. In addition, it indicated that motivation positively affected generic learning outcomes and lead to knowledge gains. The researchers anticipate that lawmakers or museum directors should be consulted to manage the use of museums for the young generation, which more likely to value the satisfying aspects of the experience, especially during the museum tour. This study gives a glimpse into the links between museum learning and ideas for future studies.
\end{abstract}

Keywords: Museum, Motivation, Satisfying Experiences, Generic Learning Outcomes

\section{Introduction}

Achieving economic well-being and improving financial capability are firmly set within current national policy agendas. Financial education is, therefore, a crucial element of creating citizens who will make a positive contribution to the world around them. However, financial education is more than just being aware of saving strategies. According to Pereira and Coelho [1], students need to understand the role of money, both at a personal level and within society. This includes appreciating the power, responsibility, benefits and challenges that money can bring and feeling confident in managing these very different associations.

Monetary museums and museums with access to a monetary collection are perfectly placed to provide a learning experience that will facilitate this appreciation. They have the unique opportunity to deliver financial education in a historical context [2], stressing money growth in culture, diverse cultural connections to the money and its role in the formation and dissolution of institutions. Taking inspiration from the collection in the Bank Negara Malaysia Museum and Art Gallery (BNM MAG) allows themes surrounding money, such as financial planning, 
economics, foreign currencies and history of money, to be explored. From this, students can develop an understanding that these apparent modern concepts have actually been experienced and evaluated over centuries.

Contextualized understanding is therefore paramount in developing an appreciation of money and the social impacts it can have, rather than simply gaining an isolated knowledge of the functions of money. This study will further explore the relationship between students' motivation, satisfying experience and generic learning outcomes contextualized financial education and the roles museum exhibitions experience play in facilitating this.

\subsection{Contextual Model of Learning}

A substantial body of literature relating to studying in physical museums and other freechoice learning contexts is now available in many cases, guided by education psychology, learning philosophy and hundreds of visitor studies. Falk and Dierking [3] formed a structure to reflect on learning, which was then called the Interactive Experience Model, and which sought to address the variety and difficulty of learning. This model was developed and improved, which led to the Contextual Model of Learning. This model has been developed by Falk and Dierking [3] and comprises 12 essential suites of factors that are classed into three contexts (Personal, Physical and Sociocultural), which influence visitors' processes of free choice education environment such as museums, both individually and collectively. There is no dominant factor, and the relationship between these factors is different to any individual. The twelve-factor suites are:

a. Personal Context

- Motivation and expectations

- Prior knowledge and experience

- Prior interests and beliefs

- Choice and control

b. Physical Context

- Advance organizers

- Orientation to the physical space

- Architecture and large-scale environment

- Design of exhibits and content of labels

- Subsequent reinforcing events and experiences outside the museum

c. Sociocultural Context

- Within group social mediation

- Facilitated mediation by others

- Cultural background and upbringing

\subsection{Motivation, Satisfying Experiences and Generic Learning Outcomes}

Motivation is a complex topic that involves understanding intrinsic versus extrinsic motivation. Intrinsic motivation is characterized by something that is inherently interesting or enjoyable, while extrinsic motivation is due to an external force or self-regulation that leads to a separable outcome [4].

Ryan and Deci [5] further mentioned that motivation is when an individual is moved to do something and can vary based on level and orientation, the reasons for behaviour are concerned with the fundamental attitudes and goals leading to action, that is.

Rowe and Nickels [5] argued that every visitor comes to the museum with a mixture of motivations such as the desire to learn something new, a social interaction, or have a relaxing 
experience, but certain motivations are more important depending on the context of the visit. Rowe and Nickels [5] identified the motive as an overarching hypothesis that was articulated during a visit that would directly affect the way visitors perform their visits and the meanings they will conclude from experience. Anderson and Ellenbogen [6] focused that motivation, along with the physical environment, social context, and personal interest, is one factor that can influence how a museum visit will impact a visitors' experience and learning.

Meanwhile, satisfying experiences in museums have the potential to influence visitors' learning and, therefore, long-term overall well-being. Pekarik et al. [7] created a structure for satisfying encounters that incorporates four categories of valuable museum guest experiences: object experiences, cognitive experiences, introspective experiences, and social experiences.

Doering [8] suggested that museums should design spaces to specifically elicit these four experiences as they produce beneficial outcomes for the visitor [9]. These four types of satisfying experiences are also dependent on experiencing various positive emotions such as experiencing beauty, feeling a sense of connectedness, or recalling memories [7][8]. The presence of positive emotions within these four satisfying experiences strengthens their impact on visitors' learning.

Thus, creating a well-managed customer experience gives museums a competitive edge [22]. Asquith [10] argued that by creating an overall 'experience,' a museum can attract visitors, encourage repeat visitation, and hold visitors' attention in exhibit elements. Ensuring that visitors have positive social interactions increases the likelihood of positive overall experiences.

Additionally, different content has varying intrinsic value to visitors based on their own personal connections and ability to have meaningful experiences [11]. Engaging with an exhibit can create a positive experience, and visitors may recall pleasant memories to make sense of an exhibit [12]. Interactive exhibits facilitate hands-on experiences [12], which allow visitors to try new things, be good at something, or participate in a satisfying experience [13].

Falk and Dierking's [3] tourist experience have also been an important and complicated research area for many years. Given that discovering and acquiring new skills is one of the primary motivations for visiting museums [14], this article reflects on the visitor's learning experience. It is worth pointing out in this sense that museum learning is optional, accessible and driven by the choices made by the visitor.

Several scholars, including Gammon [15] and Hooper-Greenhill et al. [16], suggested models that quantify visitor learning. This study focuses on Hooper-Greenhill et al. [16] model of GLO (Generic Learning Outcomes. In reality, this model highlights two dimensions: analytic and sensitive, in conformity with the work discussed in Tillon, Marchal and Houlier [17]. These dimensions shape the perspective of the tourist resulting from the encounter with exhibits. The UK Museum, Library and Archives Ministry (MLA) introduced GLO. It is also used extensively in many UK museums and has been successfully implemented by the MLA mediation services [18]. GLO's paradigm has been identified as an experience for HooperGreenhill et al. [16], which include: enhanced knowledge and comprehension, extra skills, changing attitudes and values, feeling of enjoyment, motivation and creativity, and incentives for activity and advancement.

The thesis focuses on a particular visiting encounter: the learning experience since research has been conducted in museology with Pekarik, Doering and Karns [7], Kotler [19] and Packer and Ballantyne [14] in various kinds of visitor encounters. In fact, the writers of these articles regard learning experience as one of the most important post-experiences in museums, including generic learning. There are no published reports on the motivation, satisfying experiences, and generic learning outcomes research to our knowledge; in the context of financial literacy in museums, despite the fact that some monetary and financial exhibition in museums commenced 
emerging in the recent years, which motivated us to construct a research framework (Figure 1) as follow:

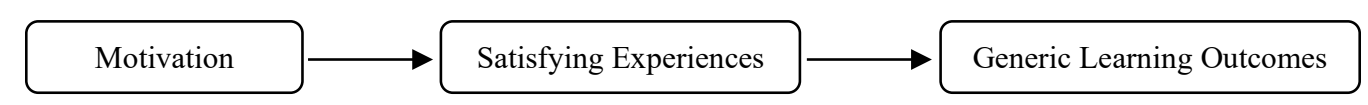

Fig. 1. Research Framework (developed by authors for current study).

Therefore, two objectives of this study were:

Objective 1: To investigate the relationship between motivation towards satisfying experiences Objective 2: To investigate the relationship between satisfying experiences towards generic learning outcomes

\section{Research Methods}

The results of the data analyzed by the approach are seen in this section, as discussed in the last section. It has a demographic profile, reliability analysis and evaluation of hypotheses in three main sections. The study results highlighted the list of observations on the motivational interaction and satisfactory experiences of students' generic learning outcomes. The mean value for each of the variables shows the students' answer to generic results by running the data through SPSS version 21. In order to test the mentioned theories, a correlation and a multiple regression analysis are used on variables.

During the trip to the Bank Negara Malaysia Museum and Art Gallery (BNM MAG) under the subject code FIN435 (Financial Market and Banking Services), the respondents were sampled as they took part in the project. Their input on some of the motivation issues and satisfactory experience were recorded using a Google Form. They also spoke about their opinions about the generic outcomes of learning. Thus, the data on the questions posed in the questionnaires have analytical credibility.

\section{Result and Discussion}

Out of the 80 questionnaires distributed, 62 respondents responded, resulting in a $77.5 \%$ response rate. From the total number of responses, all were returned in full feedback. Figure 2 shows the demographic features of the respondents.

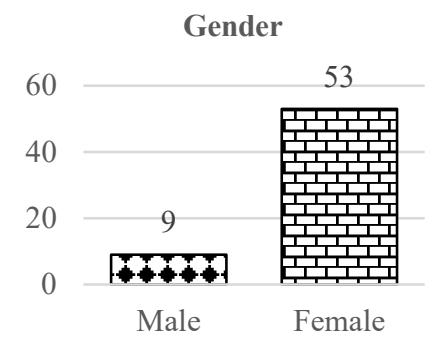

Fig. 2. Gender of respondents. 
Figure 2 shows gender representation by students who were selected to respond to their museum experiences at BNM MAG. A large portion of the respondents were females, represented by 53 students or $85.5 \%$. The remaining nine students, or $14.5 \%$, were males who participated in this study.

\subsection{Reliability Analysis}

For each independent and dependent variable to answer stability, Cronbach's Alphas were measured. This test is conducted before further research to check the accuracy of variables.

Table 1. Reliability Analysis

\begin{tabular}{lc}
\hline \multicolumn{1}{c}{ Variables } & Reliability Coefficient Alpha \\
\hline Independent Variable & \\
Motivation & 0.750 \\
Satisfying experiences & 0.883 \\
& \\
Dependent Variable & \\
Generic learning outcomes & 0.902 \\
\hline
\end{tabular}

All three variables, as seen in table 1 , have a score of more than 0.7 in their alpha Cronbach with the highest Generic learning outcome rating (0.944), followed by Motivation variable results of 0.856 . The other variable represented by Satisfying experiences (0.837). In a nutshell, all of the variables mentioned above were found to be reliable, and hypothesis testing was performed.

\subsection{Hypotheses Testing}

Two theories were suggested on the basis of the aim of this analysis. Every one of the hypotheses was reiterated below, and the results were then submitted for statistical review. The correlation analysis and multiple linear regression analysis have been used to evaluate all the hypotheses.

\subsection{Correlation Analysis}

Table 2. Correlation among Motivation, Satisfying Experiences and Generic Learning Outcome

\begin{tabular}{lccc}
\hline \multicolumn{1}{c}{ Determinant } & Motivation & $\begin{array}{c}\text { Satisfying } \\
\text { experience }\end{array}$ & $\begin{array}{c}\text { Generic Learning } \\
\text { Outcomes }\end{array}$ \\
\hline $\begin{array}{l}\text { Motivation } \\
\text { Satisfying } \\
\text { experiences }\end{array}$ & $0.650^{* *}$ & $0.650^{* *}$ & $0.557^{* *}$ \\
$\begin{array}{l}\text { Generic learning } \\
\text { outcomes }\end{array}$ & $0.557^{* *}$ & & $0.725^{* *}$ \\
\hline
\end{tabular}

The magnitude of a linear between two variables was determined by a correlation coefficient. The intensity of a linear between generic learning results and two determinants was calculated in a Pearson correlation coefficient (Motivation and Satisfying experiences). Table 2 showed a favorable and meaningful correlation between overalls of independent and dependent variables at 0.01 (2-tailed) for some values between 0.5 and 0.8 , which suggests that they were a moderately strong link. The Satisfying experience correlation was $0.725(\mathrm{p}=0.000)$ which was 
the strongest relationship, followed by Motivation $(r=0.557, p=0.000)$. Hence, the research showed that there were relationships between Motivation, Satisfying experience and Generic learning outcome.

\subsection{Multiple Linear Regression Analysis}

The statistical analysis used for examining relationships between independent variables and the dependent variable is multiple linear regression analysis. Two theories were tested, specifically:

H1: There is a significant relationship between motivation towards satisfying experiences

$\mathrm{H} 2$ : There is significant relationship between satisfying experiences towards generic learning outcomes

Table 3. Relationship between Motivation towards Satisfying Experiences

\begin{tabular}{lccc}
\hline \multicolumn{1}{c}{ Determinant } & B & Beta & Sig. \\
\hline Motivation & 0.690 & 0.650 & $* *$ \\
& & & $* *$ significant \\
R-Square & 0.422 & & $\mathrm{p}<0.001$ \\
$\begin{array}{l}\text { Adjusted R-Square } \\
\text { Method: Enter }\end{array}$ & 0.412 & & \\
\hline
\end{tabular}

The enter approach was used in this standard multiple linear regression analysis to evaluate the relationship between Satisfying experience, which is called an aggregated variable, and Motivation, which acts as an independent variable. As a result, 42.2 per cent of the overall variances in the dependent variable (Generic learning outcomes) with R-Square 0.422 is explained in Table 3 in the independent variables (Motivation). Therefore, the association between Motivation and Satisfying experience was strong.

Motivation emerged as a significant determinant in explaining the Satisfying experiences, which received a p-value of 0.001 described as highly, positively and significantly linked to the dependent variable at a $1 \%$ significant level. Hence, these findings fail to discard $\mathrm{H} 1$ of the research.

Table 4. Relationship between Satisfying Experiences towards Generic Learning Outcomes

\begin{tabular}{lccc}
\hline \multicolumn{1}{c}{ Determinant } & B & Beta & Sig. \\
\hline Satisfying experiences & 0.733 & 0.725 & $* *$ \\
& & & ${ }^{* *}$ significant \\
R-Square & 0.526 & & $\mathrm{p}<0.001$ \\
Adjusted R-Square & 0.518 & & \\
Method: Enter & & & \\
\hline
\end{tabular}

The independent variables (Satisfying experiences) described 52.6 per cent of the overall variances in the dependent variable (Generic learning outcomes) with R-Square 0.526, as seen in Table 4. As a result, the relation between Satisfying experience and Generic learning outcomes was also strong.

Satisfying experiences emerged as a significant determinant in explaining the Generic learning outcomes, which received a p-value of 0.001 conveyed as highly, positively and 
significantly associated to the dependent variable at a $1 \%$ significant level. Hence, these findings fail to discard $\mathrm{H} 2$ of the research.

\section{Conclusion}

The previous literature showed different types of satisfying experiences every time they visit the museum. The literature review scenario achieved the main aim of this paper, which is to investigate the relationship between motivation towards satisfying experiences and to investigate the relationship between satisfying experiences towards generic learning outcomes.

The findings of this study are consistent with ElDamshiry and Khalil [20], which revealed the following information twofold: a significant relationship between motivation and satisfying experiences and a significant relationship between satisfying experiences and generic learning outcomes. Furthermore, this study revealed affective, cognitive, sensory and social experiences foster visitors' learning of financial knowledge.

The instrument for assessment has been created for curators and educators to use when evaluating and understanding their museum visitors within exhibits. They may find this instrument useful in examining the constructed type of visitors' experience tally with the significance of the exhibit and the items chosen for display.

This study can be used to inform museum practices in multiple ways. Motivation as a construct is related to satisfying experiences, and therefore, visitors' satisfying experiences could be reflective of generic learning outcomes. Paying attention to visitors' satisfying experiences in museums is critical in aspects of marketing and membership [21]. Enabling students to experience financial exhibitions in such a broad context will directly contribute to a deeper appreciation of it. This will further enable the outcomes of contextualized financial education sessions to be transferred to everyday interactions with financial decisions, creating more robust and reflective learning experiences.

Marketing benefits from visitors who are satisfied since they are more likely to recommend their experience to others [22]. This means that the more visitors that are recommending their positive satisfying experiences, including affective, cognitive, sensory and social experiences, the more potentials the museum will see an increase in visitor ship. Moreover, the more satisfied someone is, the more likely they are to have a return visit [22]. This means additional revenue as well as opportunities for them to become members, which increases funding and support for the museum [21]. Therefore, the museum benefits across multiple areas when visitors satisfied and learnt during their museum visit. Future research should address the issue of reflection of learning, which is currently beyond the scope of this research. Furthermore, the study audiences' interpretations and responses in relation to the use of new media and technologies in museum exhibitions can be incorporated for future studies.

Following this, the research findings are instrumental for policymakers, educationist, and those involved in developing and administering initiatives geared toward improving youth financial literacy at every level. Additionally, the findings elicited will also assist the Malaysian government in achieving the aspirations detailed in the National Strategy for Financial Literacy 2019-2023.

\section{References}

[1] M. C. Pereira and F. Coelho, "Regulatory focus, money attitudes and financial literacy: Evidence from Portuguese young adults,” J. Fam. Econ. Issues, vol. 41, no. 4, pp. 615-625, 2020. 
[2] A. Lusardi, "Financial literacy and the need for financial education: evidence and implications," Swiss J. Econ. Stat., vol. 155, no. 1, pp. 1-8, 2019.

[3] J. H. Falk and L. D. Dierking, "Learning from museums. Walnut Creek." CA: AltaMira Press, 2000.

[4] R. M. Ryan and E. L. Deci, "Intrinsic and extrinsic motivations: Classic definitions and new directions," Contemp. Educ. Psychol., vol. 25, no. 1, pp. 54-67, 2000.

[5] S. Rowe and A. Nickels, "Visitor motivations across three informal education institutions: An application of the identity-related visitor motivation model," Visit. Stud., vol. 14, no. 2, pp. 162 175, 2011.

[6] D. Anderson and K. M. Ellenbogen, "Learning science in informal contexts-Epistemological perspectives and paradigms," in Second international handbook of science education, Springer, 2012, pp. 1179-1187.

[7] A. J. Pekarik, Z. D. Doering, and D. A. Karns, "Exploring satisfying experiences in museums," Curator Museum J., vol. 42, no. 2, pp. 152-173, 1999.

[8] Z. D. Doering, "Strangers, guests, or clients? Visitor experiences in museums," Curator Museum J., vol. 42, no. 2, pp. 74-87, 1999.

[9] J. Packer, "Beyond learning: Exploring visitors' perceptions of the value and benefits of museum experiences," Curator Museum J., vol. 51, no. 1, pp. 33-54, 2008.

[10] R. A. Asquith, "Elements of visitor experience that affect visitor satisfaction in US museums," 2012.

[11] J. A. Veverka, "Tips and concepts for planning truly 'interpretive' exhibits," Portal, 2012.

[12] A. S. Afonso and J. K. Gilbert, "The nature of exhibits about acoustics in science and technology centres,” Res. Sci. Educ., vol. 38, no. 5, pp. 633-651, 2008.

[13] J. McGonigal, "Fiero! museums as happiness Pioneers," Museum, vol. 88, no. 2, pp. 48-53, 2009.

[14] J. Packer and R. Ballantyne, "Motivational factors and the visitor experience: A comparison of three sites," Curator Museum J., vol. 45, no. 3, pp. 183-198, 2002.

[15] B. Gammon, "Assessing learning in museum environment," A Pract. Guid. museum Eval., 2003.

[16] E. Hooper-Greenhill, "Measuring learning outcomes in museums, archives and libraries: The Learning Impact Research Project (LIRP)," Int. J. Herit. Stud., vol. 10, no. 2, pp. 151-174, 2004.

[17] A. B. Tillon, I. Marchal, and P. Houlier, "Mobile augmented reality in the museum: Can a lacelike technology take you closer to works of art?," in 2011 IEEE International Symposium on Mixed and Augmented Reality-Arts, Media, and Humanities, 2011, pp. 41-47.

[18] H. Graham, R. Mason, and N. Nayling, "The personal is still political: Museums, participation and copyright," museum Soc., vol. 11, no. 2, pp. 105-121, 2013.

[19] N. Kotler, "Delivering experience; Marketing the museum's full range of assets," Museum News, vol. 78, no. 3, pp. 30-+, 1999.

[20] K. K. H. ElDamshiry and M. H. M. Khalil, "Museum visitors learning identities interrelationships with their experiences," in Green Heritage Conference: Chance-Change-Challenge, 2018, pp. 277-314.

[21] C. Dilenschneider, "The three most important reasons to prioritize visitor satisfaction (DATA)," Collendilen, 2020. [Online]. Available: https://www.colleendilen.com/2018/04/25/threeimportant-reasons-prioritize-visitor-satisfactiondata/.

[22] T. Dirsehan and A. M. Yalçin, "Comparison between holistic museum visitors and utilitarian museum visitors," Int. J. Mark. Stud., vol. 3, no. 4, p. 78, 2011. 